\title{
Comparison of endoscopic papillary large balloon dilation with and without a prior endoscopic sphincterotomy for the treatment of patients with large and/or multiple common bile duct stones: a systematic review and meta-analysis
}

This article was published in the following Dove Medical Press journal:

Therapeutics and Clinical Risk Management

\begin{abstract}
Pan Liu',*
Huapeng Lin ${ }^{2, *}$

Yuanyuan Chen ${ }^{3}$

Yu-Shen $\mathrm{Wu}^{4}$

Maocai Tang ${ }^{5}$

Liang Lai'

'Department of Hepatobiliary

Surgery, The First People's Hospital of Neijiang, Sichuan, People's Republic of China; ${ }^{2}$ Department of Intensive Care Unit, Affiliated Hangzhou First People's Hospital, Zhejiang University School of Medicine, Zhejiang, People's Republic of China; ${ }^{3}$ Department of Oncology, The First Affiliated Hospital of Chongqing Medical University, Chongqing, People's Republic of China; ${ }^{4}$ Chongqing Key Laboratory of Molecular Oncology and Epigenetics, The First Affiliated Hospital of Chongqing Medical University, Chongqing, People's Republic of China; ${ }^{5}$ Department of Gastrointestinal Surgery, Chongqing University Cancer Hospital,

Chongqing, People's Republic of China

*These authors contributed equally to this work
\end{abstract}

Correspondence: Liang Lai Department of Hepatobiliary Surgery, The First People's Hospital of Neijiang, Hanan Avenue No 1866, Neijiang, Sichuan 641000, People's Republic of China

Tel +8608322103876

Fax +8608322103876

Email lailiangnjyy@I63.com
Aim: To compare endoscopic papillary large balloon dilation (EPLBD) alone with EPLBD following endoscopic sphincterotomy (EST) in patients with large and/or multiple common bile duct stones.

Methods: We conducted a comprehensive search of PubMed, EMBASE, and the Cochrane Library database to identify relevant available articles until July 19, 2018. Complete common bile duct stone (CBDS) removal rate, frequency of mechanical lithotripsy (ML) usage, total procedure time and intra- and postoperative adverse events were analyzed. We used RevMan 5.3 to perform the pooled analyses.

Results: Seven RCTs matched the selection criteria. A total of 369 patients underwent EPLBD alone, and 367 patients underwent EPLBD following EST. Our meta-analysis revealed that there were no significant differences in terms of initial success rate $(\mathrm{OR}=0.69,95 \% \mathrm{CI}=0.44-1.09$, $P=0.11)$, frequency of $M L$ usage $(\mathrm{OR}=1.18,95 \% \mathrm{CI}=0.68-2.05, P=0.55)$, rate of post-endoscopy pancreatitis $(\mathrm{PEP})(\mathrm{OR}=0.88,95 \% \mathrm{CI}=0.43-1.78, P=0.72)$, total procedure time $(\mathrm{MD}=1.52$, $95 \% \mathrm{CI}=-0.13-3.17, P=0.07)$, or other intra- and postoperative adverse events between the groups for patients with large and/or multiple CBDSs.

Conclusions: EPLBD alone was comparable to EPLBD with prior EST in patients with large and/or multiple CBDSs. Further studies are required to confirm the mechanisms of PEP in patients who accept EPLBD during endoscopic retrograde cholangiopancreatography (ERCP). Keywords: endoscopic retrograde holangiopancreatography, ERCP, endoscopic papillary large balloon dilation, EPLBD, endoscopic sphincterotomy, EST, common bile duct stone, CBDS, meta-analysis

\section{Introduction}

Since endoscopic sphincterotomy (EST) was first reported in 1974 by Kawai et al, ${ }^{1}$ it has gradually become a well-established treatment option for common bile duct stones (CBDSs). Endoscopic papillary balloon dilation (EPBD) was first introduced in 1982 by Staritz et al. ${ }^{2}$ Due to the advantages of reduced risks of bleeding and perforation ${ }^{3}$ and the successful application in patients with surgically altered anatomy, ${ }^{4}$ EPBD is an alternative to EST in patients with choledocholithiasis. EPBD protects the function of papillary sphincter; however, it may be accompanied by increased rates of post-endoscopic pancreatitis (PEP). ${ }^{5}$ 
Endoscopic papillary large balloon dilation (EPLBD) with prior EST was introduced in 2003 by Ersoz et al ${ }^{6}$ for the treatment of patients with unsuccessful extraction of large CBDSs by EST and standard basket/balloon. Although EST with a large incision may be effective to achieve stone clearance and may have a clearance rate similar to that of EPLBD with prior EST for large and/or multiple CBDSs, the former procedure increases the risk of adverse events such as bleeding and perforation and more mechanical lithotripsy (ML) would be required. ${ }^{7}$ As for EPLBD vs EPBD use in patients with large and/or multiple CBDSs, EPLBD has been proven to require fewer endoscopy sessions and lower frequency of ML usage. ${ }^{8,9}$

After years of application and development, EPLBD with prior EST gradually became a widely used technique for treatment of large and/or multiple CBDSs because of its safety and efficacy. ${ }^{10-12}$ With the development of therapeutic principle, simplified procedures and assurance of therapeutic effects in strategies of endoscopic procedures were required, EPLBD alone gradually became an attractive option. ${ }^{13}$ The international consensus guidelines for EPLBD ${ }^{12}$ and the Japan Gastroenterological Endoscopy Society guidelines for EPLBD $^{11}$ both suggested that EPLBD can be successfully used for large and/or multiple CBDSs with or without EST; however, the evidence level about whether EST is necessary was low. Meanwhile, EPLBD with prior EST was thought to improve the clearance rate in the initial session and might reduce the usage of ML. Recently, the results of a randomized controlled trial (RCT) with 200 patients were published by Park et al, ${ }^{13}$ the results for EPLBD alone and EST with EPLBD were similar in their study.

Due to these conflicting findings and the outcomes reported in the RCT, we carried out a meta-analysis to compare EPLBD alone with EPLBD following EST in patients with large and/or multiple CBDSs, in terms of initial success rate, the frequency of ML usage, total procedure time and rate of PEP and other intra- and postoperative adverse events.

\section{Methods and materials Search strategies}

The present research was conducted according to the PRISMA statement. ${ }^{14}$ Two authors searched electronic databases, including MEDLINE, EMBASE, and the Cochrane Library to identify relevant articles until July 19, 2018. The search terms included: "balloon dilation," "balloon dilatation," "endoscopic papillary balloon dilation," "endoscopic papillary balloon dilatation," "endoscopic papillary large balloon dilation," "endoscopic papillary large balloon dilatation," "EPBD" and "EPLBD" combined with the terms "sphincterotomy," "EST," and "ES." Furthermore, ClinicalTrials.gov and the reference lists of included studies were reviewed. The searches were limited to articles published in English.

\section{Inclusion and exclusion criteria}

The inclusion criteria were as follows: 1) EPLBD with or without EST was used in patients suffering from large (no less than $10 \mathrm{~mm}$ ) or multiple CBDSs; 2) the diameter of the balloon was no less than $10 \mathrm{~mm}$; 3) the study included a comparison of EPLBD alone and EPLBD with prior EST; 4) patients were aged 18 years or older; 5) study was a randomized clinical trial (RCT); 6) study presented at least one outcome of interest. The exclusion criteria were as follows: 1) non-RCT; 2) duplicated report. Two investigators scrutinized the titles and abstracts of all identified articles to exclude irrelevant studies first and then read the full texts to further exclude unqualified studies. A third author would intervene if consensus was not reached.

\section{Data extraction and quality assessment}

Data extraction was carried out by predesigned forms. One author extracted the following data that was checked carefully by other authors: 1) basic information about the included studies (study design, study comparison, inclusion criteria of CBDSs, diameter of the balloon used in both groups, and whether post-procedure biliary drainage was used); 2) demographics and clinical characteristics of the patients (stone size, maximum CBDS diameter, number of periampullary diverticula, and total bilirubin prior to procedure); 3) intraoperative and postoperative outcomes (initial success rate, overall success rate, no of sessions for complete stone removal, total adverse events, frequency of ML usage, rate of PEP, bleeding, and perforation).

\section{Statistical analysis}

The meta-analysis was conducted using RevMan software version 5.3 (The Nordic Cochrane Center, Cochrane Collaboration, Copenhagen, Denmark). A quantitative statistical analysis for dichotomous variables was carried out using the odds ratio (OR) as the summary statistic. Mean differences (MDs) were used as the summary statistic for quantitative analysis of continuous variables. Both the $\mathrm{OR}$ and $\mathrm{MD}$ values were reported as $95 \%$ CI. For those studies comprising continuous data, the mean and SD were calculated using the 
methods described by Hozo et $\mathrm{al}^{15}$ if necessary. The level of heterogeneity between studies was evaluated by $I^{2}$ statistics. $I^{2}<30 \%$ was considered to be low heterogeneity, $30 \% \leq$ $I^{2} \leq 50 \%$ was considered to be moderate heterogeneity, and $I^{2}>50 \%$ represented high heterogeneity. A randomeffects model was applied for all comparisons. Statistical significance across the studies was defined as $P<0.05$.

\section{Sensitivity analysis and assessment of the risk of bias}

Sensitivity analysis was performed by removing one study at a time to assess whether the results could be markedly affected by a single study. The Cochrane collaboration tool, which is an instrument for assessing the quality of RCTs, was used to assess the risk of bias for quality assessment of the included trials.

\section{Results}

According to the search strategy, a total of 1,163 articles were identified, of which 371 were excluded after deduplication. We then excluded 638 articles that were irrelevant to the topic based on the title and abstract, leaving out 154 articles. Of these, only seven RCTs ${ }^{13,16-21}$ (including one conference abstract) were finally included in this meta-analysis after full-text assessment. A study selection flow diagram and reasons for final exclusion are shown in Figure 1.

Seven RCTs included 976 patients in all, and the sample sizes ranged from 60 to 255 . The studies were published

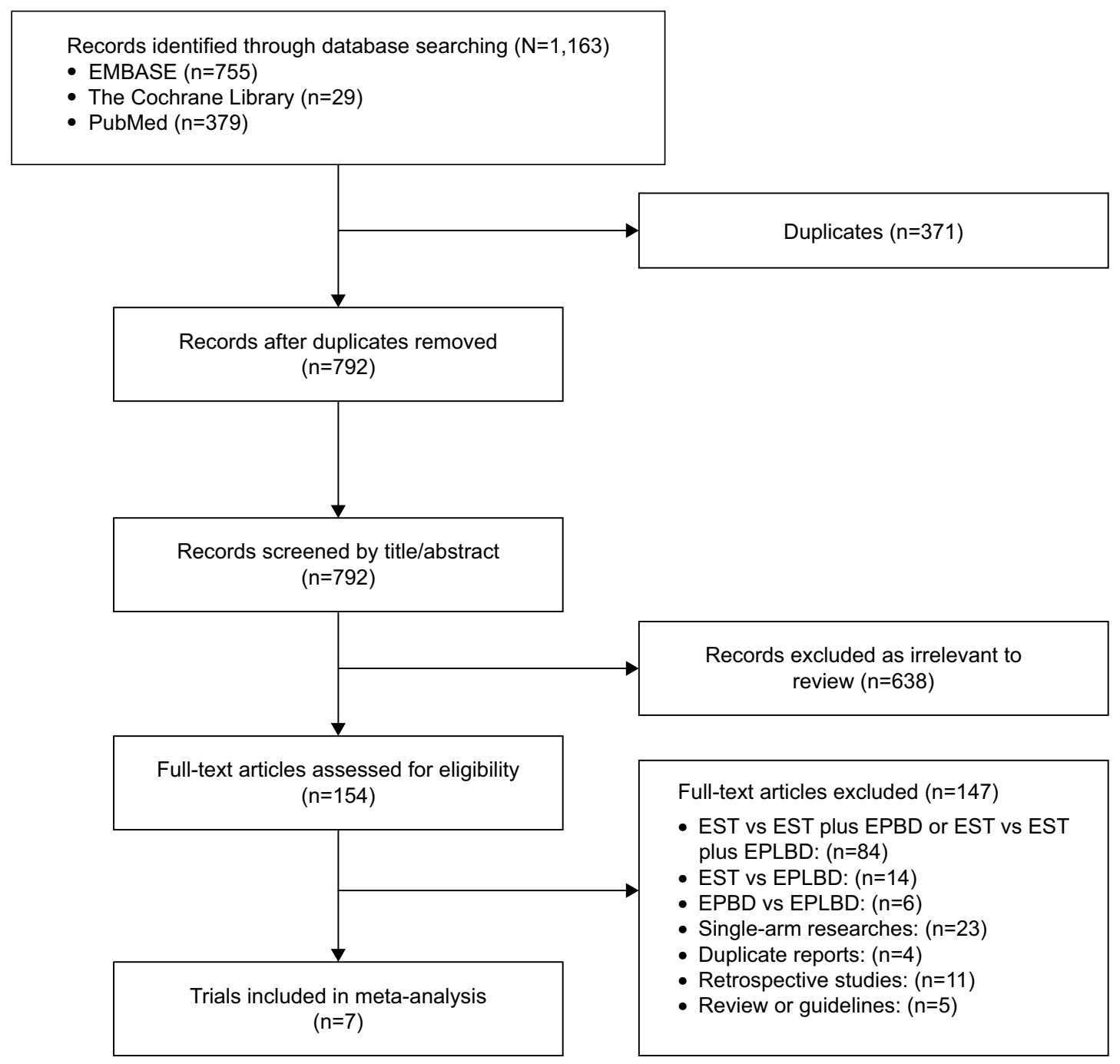

Figure I Study selection process.

Notes: From Moher D, Liberati A, Tetzlaff J, Altman DG, The PRISMA Group (2009). Preferred Reporting Items for Systematic Reviews and Meta-analyses: The PRISMA Statement. PLoS Med 6(6):el000097. doi:10.137I/journal.pmed I000097. For more information, visit www.prisma-statement.org.

Abbreviations: EPBD, endoscopic papillary balloon dilatation; EPLBD, endoscopic papillary large balloon dilatation; EST, endoscopic sphincterotomy. 
between 2013 and 2018, and study periods ranged from 2009 to 2015 . Only 736 patients were included in the present comparisons. Of these, 369 underwent EPLBD alone, and 367 underwent EPLBD following EST for CBDSs removal. Seven trials were performed in three different countries (three in South Korea, two in China, and two in Egypt). For the study design of the seven including trials, Chu et $\mathrm{a}^{21}$ conducted a 4-arm parallel-group trial comparing the efficacies of EST alone, EPLBD alone, EST plus EPLBD, and EPLBD plus EST (EST plus EPLBD: EST followed by EPLBD, EPLBD plus EST: EPLBD followed by EST); El Wakil et a $1{ }^{17}$ Sarhan et a ${ }^{18}$ and Guo et al ${ }^{19}$ conducted 3 -arm trials comparing EST alone, EPLBD alone, EST with EPLBD, respectively. The remaining three studies ${ }^{13,16,20}$ performed in South Korea were 2-arm trials comparing EPLBD alone vs EPLBD following EST. The inclusion criteria of CBDSs were the maximum CBDS size of at least $\geq 10 \mathrm{~mm}$ (found in most studies ${ }^{13,19,21}$ but $\geq 12 \mathrm{~mm}$ in two studies). ${ }^{16,20}$ Only El Wakil et a ${ }^{17}$ took the occurrence of large and/or multiple CBDSs as an inclusion criterion of CBDS. The maximum balloon diameter used in the included studies ranged from 10 to $20 \mathrm{~mm}$. Guo et al ${ }^{19}$ and Park et $a 1^{13}$ performed post-procedure biliary drainage using nasobiliary drainage or plastic stents routinely. Chu et $\mathrm{al}^{21}$ used it based on the judgments of the treating physicians. The basic information regarding the seven included trials is presented in Table 1 and the demographics and clinical characteristics of the patients are shown in Table 2.

\section{Complete CBDSs removal rate}

For the rate of successful CBDSs removal in the initial session, all seven studies ${ }^{13,16-21}$ reported this outcome, and there was no heterogeneity $\left(I^{2}=0 \%, P=0.98\right)$. The initial success rate was lower in the EPLBD alone groups (316/369, $85.9 \%)$ than in the EST with EPLBD groups $(328 / 367$, $89.3 \%$ ); however, the combined result was not statistically significant $(\mathrm{OR}=0.69,95 \% \mathrm{CI}=0.44-1.09, P=0.11$ ) (Table 3, Figure 2A). Two studies provided data regarding overall success rate by carrying out multiple sessions. In Park et al's study, ${ }^{13}$ the overall success rate of CBDSs removal completely in EPLBD alone group was 92\% (92/100) with 77 patients accomplishing this in the first session; 14 patients had two sessions and 1 patient had three sessions. The overall success rate in EST with EPLBD group was 88\% (88/100) (78 patients with one session, 7 patients with two sessions, and 3 patients with three sessions). In Chu et al's study, ${ }^{21}$ the overall success rate was 97\% (29/30) in the EPLBD alone group (20 patients with one session, 4 patients with two sessions, and 5 patients with three sessions) and $94 \%(31 / 33)$ in

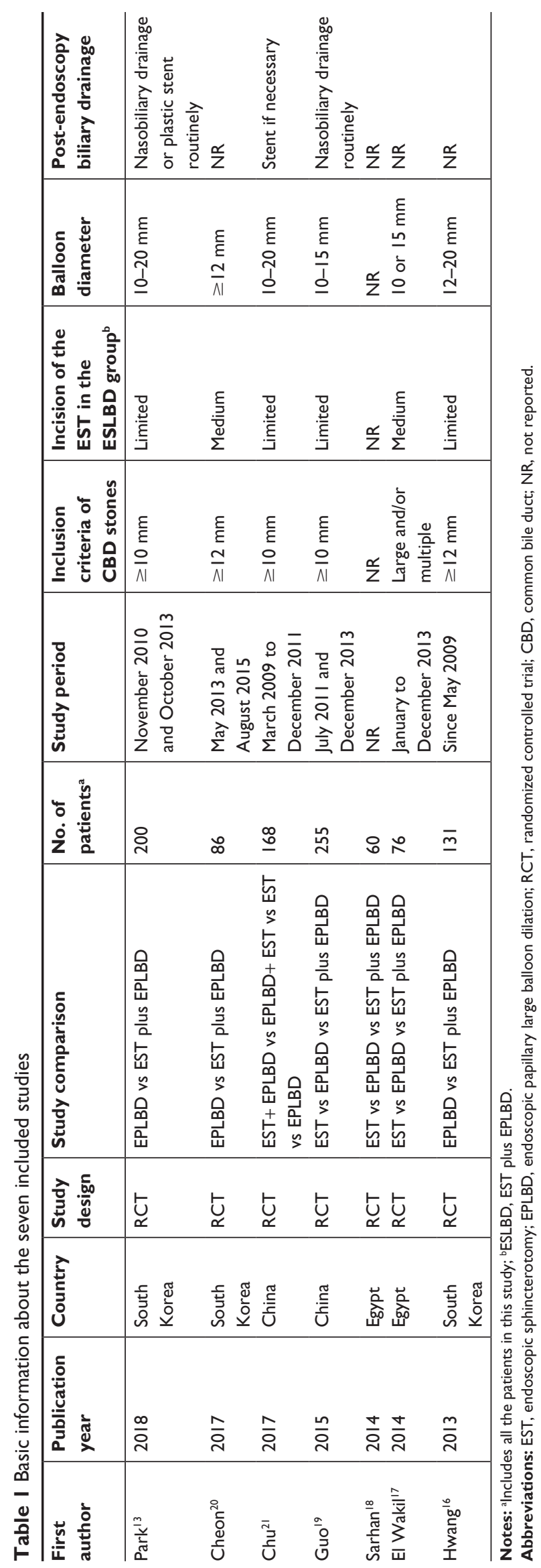




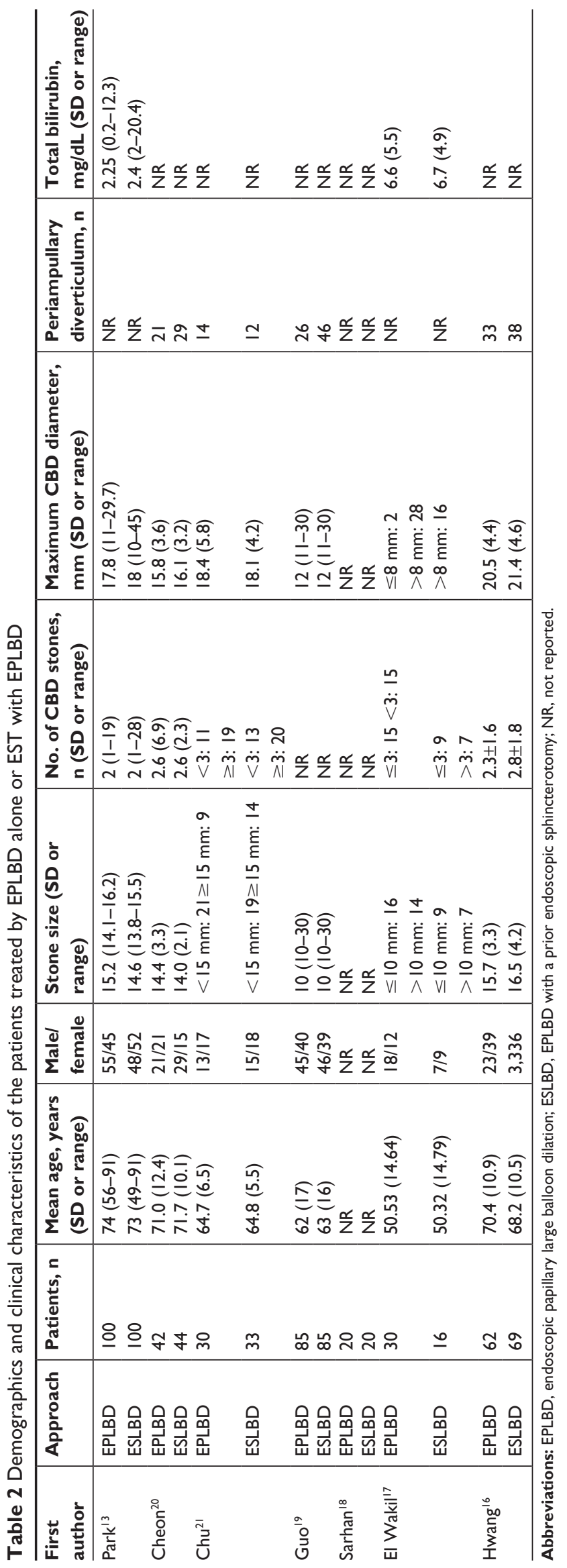

EST with EPLBD group (26 patients with one session and 5 patients with two sessions) (Table 3 ).

\section{The frequency of mechanical lithotripsy usage}

In terms of the use of ML, six studies ${ }^{13,16,17,19-21}$ provided data for this outcome with low heterogeneity $\left(I^{2}=14 \%, P=0.32\right)$. The rate was lower in the EST with EPLBD group (36/330, $10.9 \%$ ) than in the EPLBD alone group (42/338, 12.4\%); however, the combined result was not statistically significant $(\mathrm{OR}=1.18,95 \% \mathrm{CI}=0.68-2.05, P=0.55)$ (Table 3, Figure 2B).

\section{Post-endoscopy pancreatitis}

All seven trials ${ }^{13,16-21}$ provided data for this outcome with no heterogeneity $\left(I^{2}=0 \%, P=0.68\right)$. The rate of PEP was $5.1 \%$ $(19 / 369)$ in the EPLBD alone group and 4.9\% (18/367) in the EST with EPLBD group. In all cases, no patients suffered from severe or hemorrhagic PEP and all recovered with conservative treatment. The pooled data revealed that the result was not statistically significant $(\mathrm{OR}=0.88$, 95\% CI=0.43-1.78, $P=0.72$ ) (Table 3, Figure 2C).

\section{Total procedure time}

Three trials ${ }^{13,19,20}$ provided data for this outcome, and no heterogeneity $\left(I^{2}=0 \%, P=0.48\right)$ was found. The pooled data demonstrated that the result was not statistically significant $(\mathrm{MD}=1.52,95 \%=-0.13-3.17, P=0.07)$ (Table 3, Figure 2D).

\section{Other complications}

In terms of total intra- and postoperative adverse events, the present meta-analysis revealed that the result was not statistically significant between groups $(\mathrm{OR}=1.15$, $95 \% \mathrm{CI}=0.62-2.15, P=0.66$ ) (Table 3 , Figure $3 \mathrm{~A}$ ). The rate of post-endoscopy cholangitis was $2.1 \%(4 / 187)$ in the EPLBD alone group and $1.7 \%(3 / 178)$ in the EST with EPLBD group; the result was also not statistically significant $(\mathrm{OR}=1.01$, $95 \% \mathrm{CI}=0.23-4.36, P=0.99$ ) (Table 3, Figure 3B). The rate of bleeding was $0.5 \%$ in both groups $(2 / 369$ in the EPLBD alone group and 2/367 in the EST with EPLBD group). The rate of perforation was $0.3 \%(1 / 367)$ in the EST with EPLBD group with no patient suffering from perforation in the EPLBD alone group.

\section{Sensitivity analysis and assessment of the risk of bias}

Sensitivity analysis was performed by sequentially removing one trial at each turn to assess whether a single study 
Table 3 Intraoperative and postoperative outcomes

\begin{tabular}{|c|c|c|c|c|c|c|}
\hline First author & Approach & Patients, $\mathbf{n}$ & $\begin{array}{l}\text { Initial success, } \\
\text { n (\%) }\end{array}$ & $\begin{array}{l}\text { Overall success, } \\
\text { n (\%) }\end{array}$ & $\begin{array}{l}\text { No. of sessions for } \\
\text { complete stone } \\
\text { removal, n/times }\end{array}$ & $\begin{array}{l}\text { Total adverse } \\
\text { events, } n\end{array}$ \\
\hline \multirow[t]{2}{*}{ Park $^{13}$} & EPLBD & 100 & $77(77.0)$ & 92 & $77 / I, I 4 / 2, I / 3$ & 6 \\
\hline & ESLBD & 100 & $78(78.0)$ & 88 & $78 / 1,7 / 2,3 / 3$ & 4 \\
\hline \multirow[t]{2}{*}{ Cheon $^{20}$} & EPLBD & 42 & $40(95.2)$ & - & - & 5 \\
\hline & ESLBD & 44 & 43 (97.7) & - & - & 5 \\
\hline \multirow[t]{2}{*}{$\mathrm{Chu}^{21}$} & EPLBD & 30 & $20(66.7)$ & 29 & $20 / 1,4 / 2,5 / 3$ & 4 \\
\hline & ESLBD & 33 & $26(78.8)$ & 31 & $26 / 1,5 / 2$ & 2 \\
\hline \multirow[t]{2}{*}{ Guo'19 } & EPLBD & 85 & 78 (91.8) & - & - & 4 \\
\hline & ESLBD & 85 & $82(96.5)$ & - & - & 5 \\
\hline \multirow[t]{2}{*}{ Sarhan ${ }^{18}$} & EPLBD & 20 & $19(95.0)$ & - & - & NR \\
\hline & ESLBD & 20 & $20(100)$ & - & - & NR \\
\hline \multirow[t]{2}{*}{ El Wakil ${ }^{17}$} & EPLBD & 30 & $22(73.3)$ & - & - & NR \\
\hline & ESLBD & 16 & $13(81.3)$ & - & - & NR \\
\hline \multirow[t]{2}{*}{ Hwang ${ }^{16}$} & EPLBD & 62 & $60(96.8)$ & - & - & 4 \\
\hline & ESLBD & 69 & 66 (95.7) & - & - & 5 \\
\hline \multirow[t]{2}{*}{ Total } & EPLBD & 369 & $316(85.6)$ & - & - & $23 / 319(7.2)$ \\
\hline & ESLBD & 367 & $328(89.3)$ & - & - & $21 / 331(6.3)$ \\
\hline
\end{tabular}

Note: ${ }^{a}$ Only trials stating complete stone removal was achieved by multiple sessions were included.

Abbreviations: EPLBD, endoscopic papillary large balloon dilation; ESLBD, EPLBD with a prior endoscopic sphincterotomy; NR, not reported.

would markedly affect the results. Sensitivity analysis suggested that the results in this meta-analysis were relatively stable in almost all comparisons except for the total procedure time. When removing Cheon et al, ${ }^{20}$ total procedure time was significantly longer in the EPLBD alone group than in the EST with EPLBD group (OR $=2.28,95 \%$ $\mathrm{CI}=0.21-4.35, P=0.03$ ) (Figure 3C). The risk of bias of each trial is summarized in Figure 4. In general, trials included in the present meta-analysis were classified as moderate or high quality.

\section{Discussion}

The present meta-analysis revealed that there were no significant differences in terms of initial success rate $(\mathrm{OR}=0.69,95 \% \mathrm{CI}=0.44-1.09, P=0.11)$, frequency of ML usage $(\mathrm{OR}=1.18,95 \% \mathrm{CI}=0.68-2.05, P=0.55)$, rate of PEP $(\mathrm{OR}=0.88,95 \% \mathrm{CI}=0.43-1.78, P=0.72)$, total procedure time (MD $=1.52,95 \%=-0.13-3.17, P=0.07)$, or other intraand postoperative adverse events between EPLBD alone and EST following EPLBD for patients with large and/or multiple CBDSs. The rate of bleeding, perforation and post-endoscopy cholangitis were very low in both groups.

The superiority of EPBD or EPLBD without EST over EST or combined technique during ERCP is well known for patients with high risk of bleeding and surgically altered anatomy. ${ }^{22,23}$ For general patients with large and/or multiple CBDSs, EPLBD with or without EST was shown to be an at least equal or superior technique to EST alone or EPBD in terms of efficacy and safety. ${ }^{24}$ For EPLBD, the decision to perform prior EST is generally based on judgments of the clinicians with respect to the patients' physical conditions. Theoretically, EPLBD alone is more conveniently performed than EST with EPLBD for EST being omitted, and EPLBD alone is more frequently performed in patients with high risk of bleeding such as liver cirrhosis or antiplatelet drug use. ${ }^{12,25}$ On the other hand, EPLBD following limited or medium EST can provide a larger orifice that may make it more convenient to remove the CBDSs and it may reduce the procedure time and number of endoscopic sessions required for complete stone removal. The result of pooled data in two included trials ${ }^{13,21}$ showed that $19.8 \%(24 / 121)$ of patients in the EPLBD alone group and $13.2 \%$ (15/114) of patients in the EST with EPLBD group required more than one session for total CBDSs clearance. The present meta-analysis demonstrated that there were no significant differences in initial success rate $(\mathrm{OR}=0.69,95 \% \mathrm{CI}=0.44-1.09, P=0.11)$ or total procedure time $(\mathrm{MD}=1.52,95 \%=-0.13-3.17, P=0.07)$. These results may be explained by the notion that EPLBD alone may be more convenient to perform but more sessions may be required for total CBDSs clearance than EPLBD with a prior EST.

The mechanisms of PEP are not clearly defined, it was widely believed to be related to the compression on the pancreatic duct by balloon during dilation previously. For this reason, EST before EPLBD with a limited or medium incision in the direction of 11 or 12 points was thought to 


\begin{tabular}{|c|c|c|c|c|c|c|}
\hline $\begin{array}{l}\text { Mechanical lithotripsy, } \\
\text { n/patients included (\%) }\end{array}$ & $\begin{array}{l}\text { Total procedure } \\
\text { time (SD or range) }\end{array}$ & $\begin{array}{l}\text { Pancreatitis, } \\
\text { n (\%) }\end{array}$ & $\begin{array}{l}\text { Asymptomatic } \\
\text { hyperamylasemia, n (\%) }\end{array}$ & $\begin{array}{l}\text { Bleeding, } \\
\text { n (\%) }\end{array}$ & $\begin{array}{l}\text { Perforation, } \\
\text { n (\%) }\end{array}$ & $\begin{array}{l}\text { Cholangitis, } \\
\text { n (\%) }\end{array}$ \\
\hline $6 / 92(6.5)$ & $20.5(2.35-57.4)$ & $\mathrm{I}(\mathrm{I} .0)$ & $2(2.0)$ & 0 & 0 & $N R$ \\
\hline $8 / 88(9.1)$ & $18.0(2.0-58.3)$ & $3(3.0)$ & 0 & 0 & 0 & NR \\
\hline $9 / 42(21.4)$ & $10.8(6.9)$ & $3(7.1)$ & NR & I (2.4) & 0 & I \\
\hline $6 / 44(13.6)$ & $10.6(5.7)$ & $5(I I .4)$ & $N R$ & I (2.3) & 0 & 0 \\
\hline $4 / 29(13.8)$ & NR & $3(10.0)$ & I (3.3) & 0 & 0 & 0 \\
\hline $0 / 31(0)$ & $N R$ & $0(0)$ & I (3.0) & 0 & 0 & I \\
\hline I2/85 (I4.I) & $22(10)$ & $2(2.4)$ & $N R$ & I (I.2) & 0 & I \\
\hline $7 / 85$ (8.2) & $20(10)$ & $2(2.4)$ & NR & $\mathrm{I}(1.2)$ & 0 & 2 \\
\hline NR & $N R$ & I (5.0) & NR & 0 & 0 & NR \\
\hline NR & NR & I (5.0) & NR & 0 & 0 & $N R$ \\
\hline $1 / 30(3.3)$ & NR & $5(16.7)$ & $7(23.3)$ & 0 & 0 & 2 \\
\hline $0 / 16(0)$ & $N R$ & $4(30.8)$ & $3(18.8)$ & 0 & 0 & 0 \\
\hline $10 / 60(16.7)$ & $N R$ & $4(6.7)$ & NR & 0 & 0 & NR \\
\hline $15 / 66$ (22.7) & NR & $3(4.3)$ & NR & 0 & 1 & NR \\
\hline $42 / 338(12.4)$ & - & $19 / 369(5.1)$ & - & $2 / 369(0.5)$ & $0 / 369(0.0)$ & $4 / 187(2.1)$ \\
\hline $36 / 330(10.9)$ & - & I8/367 (4.9) & - & $2 / 367(0.5)$ & I/367 (0.3) & $3 / 178$ (1.7) \\
\hline
\end{tabular}

reduce pressure on the pancreatic duct by the balloon and the pressure of the balloon could be released in the direction of the incision. Thus, EPLBD following EST was thought to reduce the risk of PEP. Nevertheless, current studies suggested that EPLBD alone is safe and effective to treat large CBDSs without increasing the rate of PEP. ${ }^{26}$ Fujisawa et $\mathrm{al}^{27}$ reviewed studies of balloon dilation and reevaluated the incidence of PEP, and concluded that PEP may not be caused by papillary damage, suggesting that the catheterization of the EPLBD was not the main reason for PEP, whereas the frequency of ML usage and total procedure time may be the main reasons for patients suffering from PEP. In addition, Park et $\mathrm{al}^{28}$ performed a multicenter retrospective study with 946 patients who underwent EPLBD (balloon size 12-20 mm), and their results suggested that balloons $\geq 14 \mathrm{~mm}$ in diameter were associated with a lower risk of pancreatitis $(\mathrm{OR}=0.27, P=0.015)$. In our present meta-analysis, the frequency of ML usage and total procedure time were both higher in the EPLBD alone group than in the EPLBD with EST group (ML: $12.4 \%$ vs $10.9 \%$ ), and the rate of PEP was higher in the EPLBD alone group (PEP: $5.1 \%$ vs $4.9 \%$ ). Although the differences were not statistically significant, this may further prove this point of view. Further studies are needed to confirm the mechanisms of PEP in patients undergoing EPLBD during ERCP. Recent studies showed that post-endoscopy biliary drainage with nasobiliary drainage or biliary stent reduced the incidence of PEP. In an RCT performed by Huang et $\mathrm{al}^{29}$ of 160 patients in China, PEP was significantly lower in the endoscopic nasobiliary drainage (ENBD) catheter group (1.28\% vs $10.4 \% ; P=0.018)$. To avoid the occurrence of PEP, two of the included trials ${ }^{13,19}$ performed post-procedure biliary drainage routinely and Chu et $\mathrm{al}^{21}$ performed it on the judgment of the treating physicians. Besides, prophylactic pancreatic stenting has been proven effective in preventing the occurrence of PEP, and it has been recommended in all patients with pancreatic guidewire-assisted biliary cannulation. ${ }^{23}$ However, there is still a lack of relevant clinical study about prophylactic pancreatic duct stenting in EPLBD to prevent PEP. More clinical data are needed to assess its feasibility and efficacy.

Although the safety and effectiveness of EPLBD with or without EST have been proven, the contraindications to EPLBD should still be mentioned. In addition to the contraindications in patients with a high risk of bleeding during ERCP, perforation, which is a serious complication, should be mentioned. A retrospective study ${ }^{28}$ performed in South Korea revealed that distal CBD stricture independently predicted perforation. In view of this result, EPLBD is not recommended in patients with obvious stricture of the distal bile duct. ${ }^{11,12}$ Meanwhile, the functional recovery of sphincter of Oddi (SO) after EPLBD should also be noted. Cheon et $\mathrm{al}^{20}$ found that SO function was not recovered after 1 year and the loss of SO function in the EPLBD alone group and the EPLBD following EST group was persistent and comparable in their research. 
A

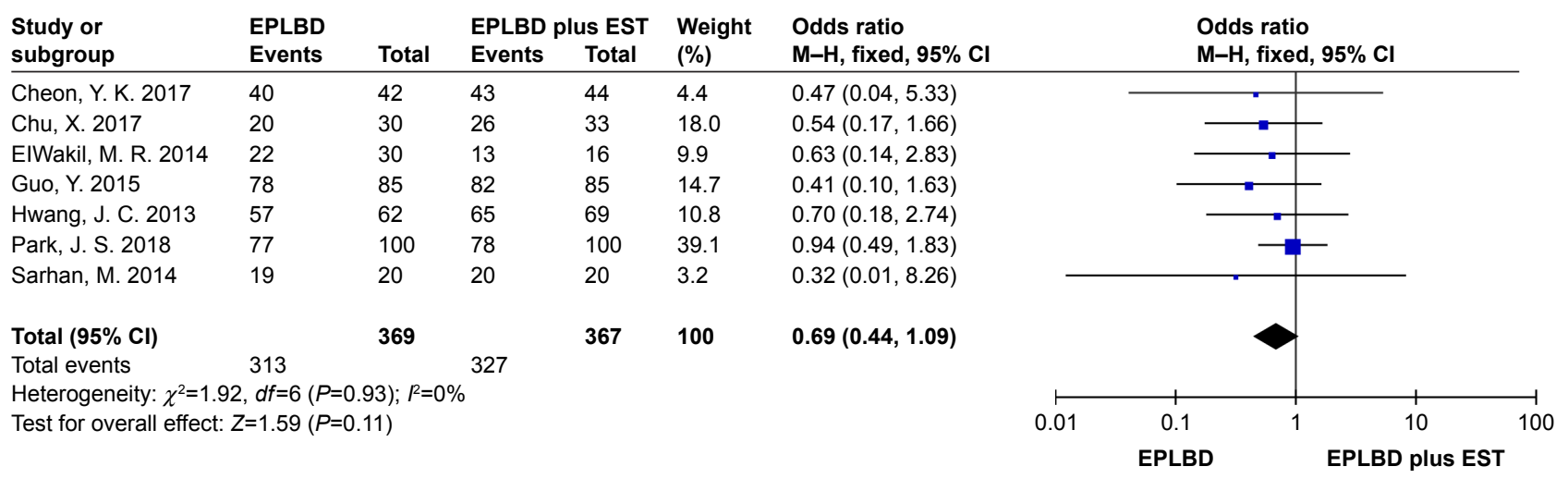

B

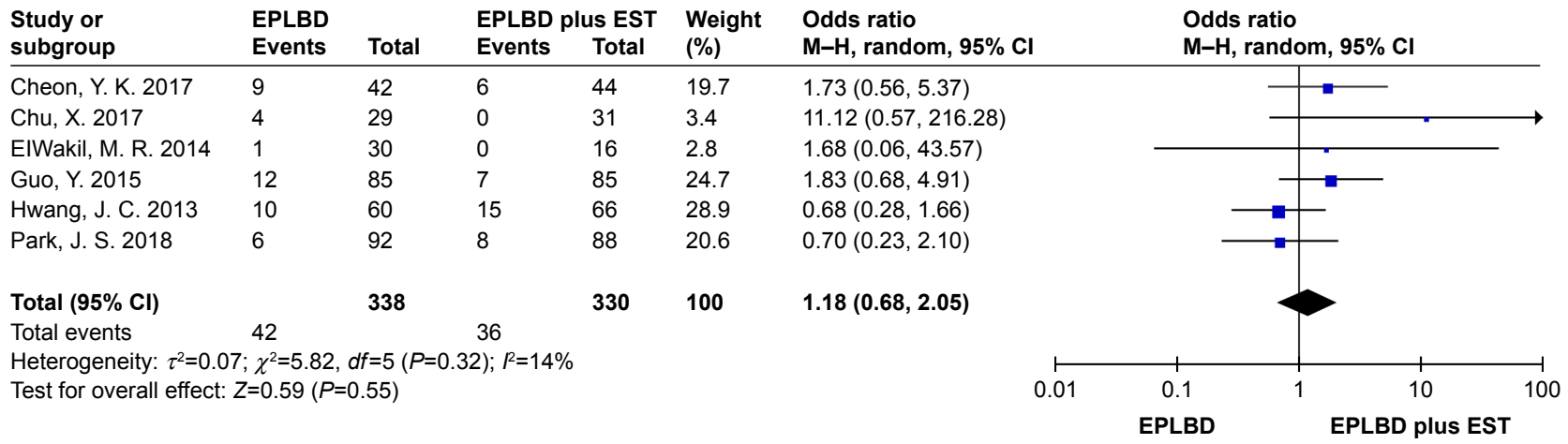

C

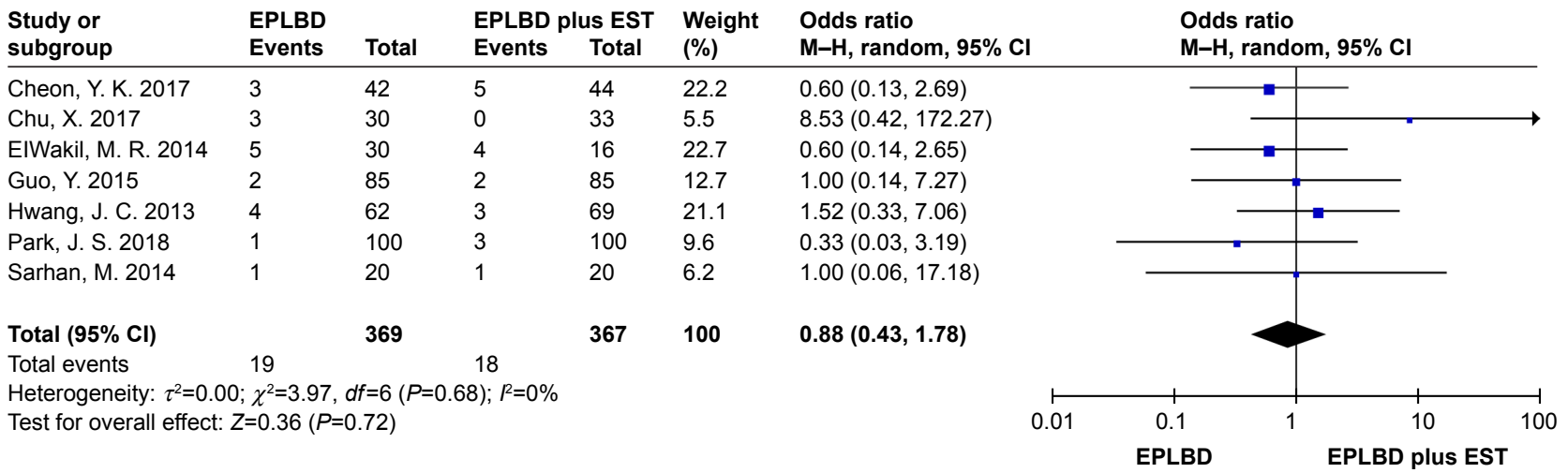

D

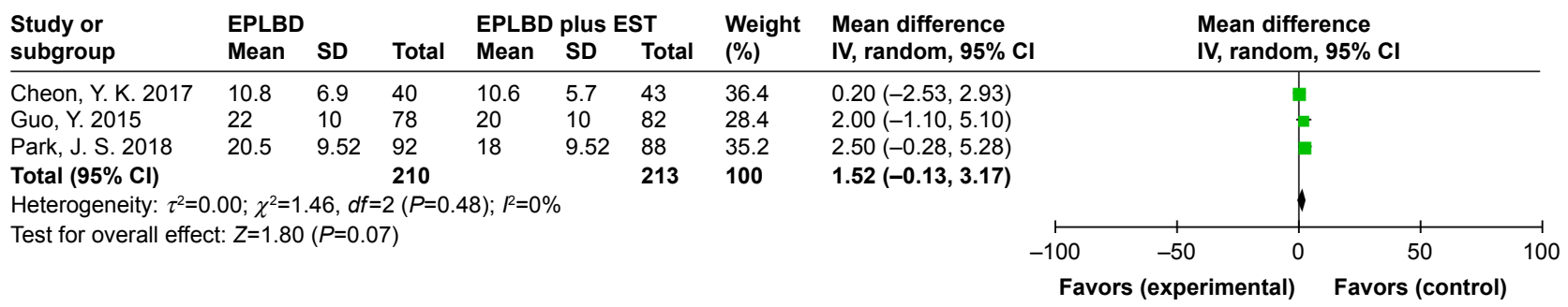

Figure 2 Forest plot of $(\mathbf{A})$ initial success, (B) frequency of mechanical lithotripsy usage, (C) post-endoscopy pancreatitis, and (D) total procedure time. Abbreviations: EST, endoscopic sphincterotomy; EPLBD, endoscopic papillary large balloon dilation. 


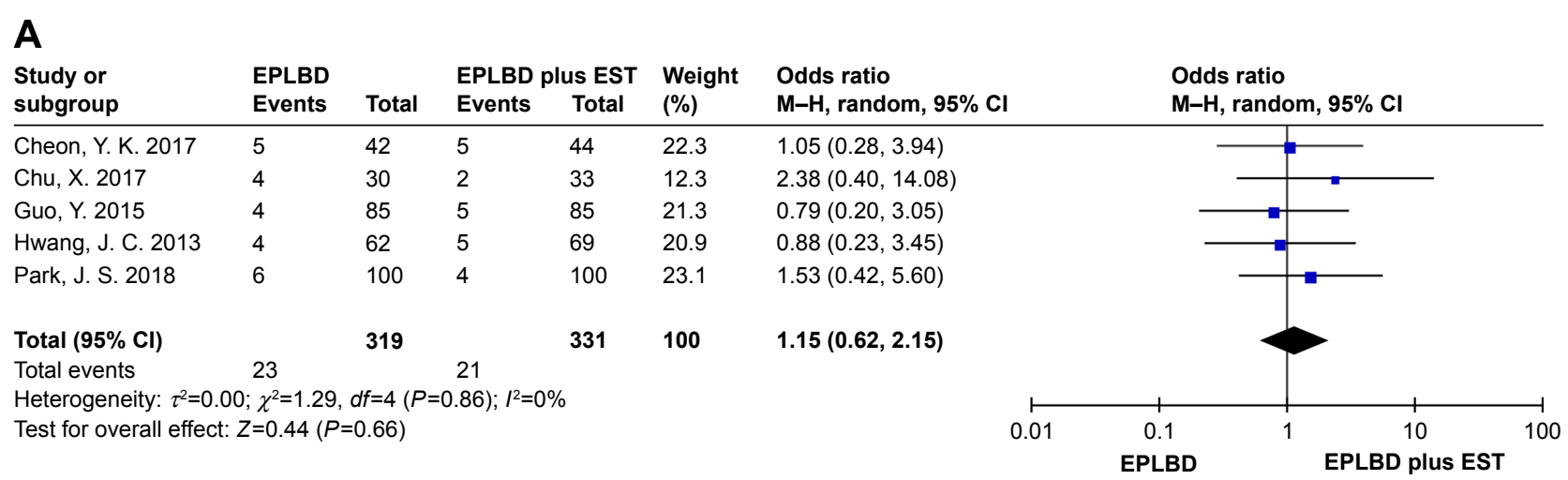

B

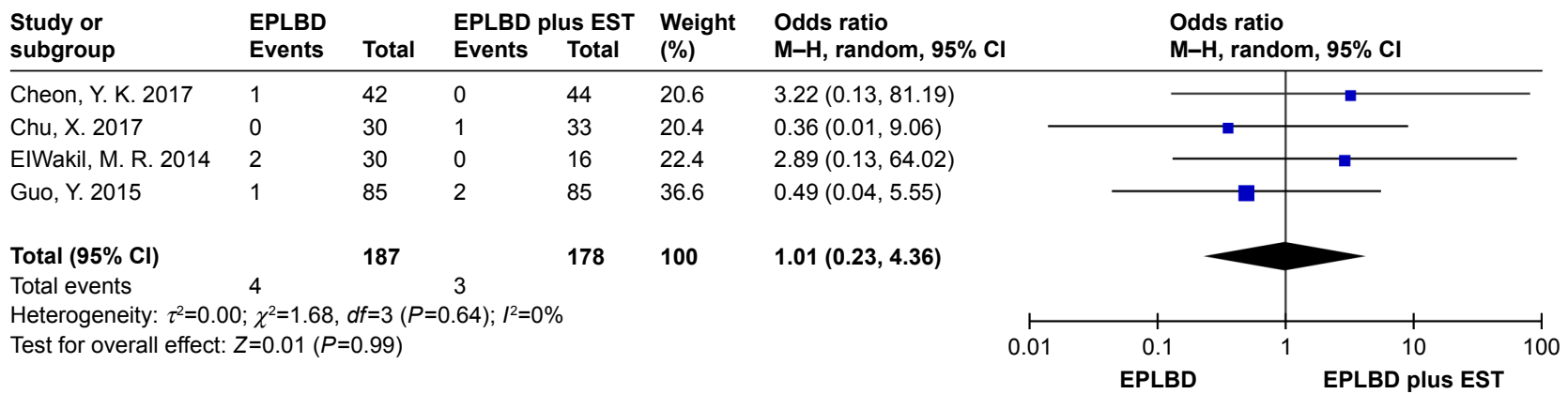

C

\begin{tabular}{|c|c|c|c|c|c|c|c|c|c|c|c|c|}
\hline $\begin{array}{l}\text { Study or } \\
\text { subgroup }\end{array}$ & $\begin{array}{l}\text { EPLBD } \\
\text { Mean }\end{array}$ & SD & Total & $\begin{array}{l}\text { EPLBL } \\
\text { Mean }\end{array}$ & $\begin{array}{l}\text { plus } E \\
\text { SD }\end{array}$ & $\begin{array}{l}\text { ST } \\
\text { Total }\end{array}$ & $\begin{array}{l}\text { Weight } \\
(\%)\end{array}$ & $\begin{array}{l}\text { Mean difference } \\
\mathrm{IV} \text {, random, } 95 \% \mathrm{CI}\end{array}$ & \multicolumn{3}{|c|}{$\begin{array}{l}\text { Mean difference } \\
\text { IV, random, } 95 \% \mathrm{CI}\end{array}$} & \\
\hline Park, J. S. 2018 & 20.5 & 9.52 & 92 & 18 & 9.52 & 88 & 55.4 & $2.50(-0.28,5.28)$ & & \multirow{3}{*}{\multicolumn{2}{|c|}{ 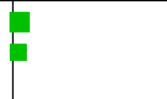 }} & \\
\hline Guo, Y. 2015 & 22 & 10 & 78 & 20 & 10 & 82 & 44.6 & $2.00(-1.10,5.10)$ & & & & \\
\hline Cheon, Y. K. 2017 & 10.8 & 6.9 & 40 & 10.6 & 5.7 & 43 & 0.0 & $0.20(-2.53,2.93)$ & & & & \\
\hline Total $(95 \% \mathrm{Cl})$ & & & 170 & & & 170 & 100 & $2.28(0.21,4.35)$ & & \multicolumn{2}{|c|}{ 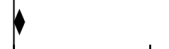 } & \\
\hline \multicolumn{8}{|c|}{ Heterogeneity: $\tau^{2}=0.00 ; \chi^{2}=0.06, d f=1(P=0.81) ; l^{2}=0 \%$} & -100 & -50 & \multirow[t]{2}{*}{0} & 50 & 100 \\
\hline & & & & & & & & & exper & & \multicolumn{2}{|c|}{ Favors (control) } \\
\hline
\end{tabular}

Figure 3 Forest plot of $(\mathbf{A})$ total adverse events, (B) post-endoscopy cholangitis, and (C) sensitivity analysis of the total procedure time. Abbreviations: EST, endoscopic sphincterotomy; EPLBD, endoscopic papillary large balloon dilation.

Finally, there were several limitations in the present meta-analysis. First, the inclusion criteria for CBDs varied across the trials, possibly leading to bias to this meta-analysis; meanwhile, the most common size was $\geq 10 \mathrm{~mm}$, and it is different from the commonly clinical endoscopy practice $(>15 \mathrm{~mm})$, and we could not proceed with further analysis based on the size of stones because of the lack of more detailed data. Second, the maximum balloon diameter used in the included trials varied, the maximum balloon diameter used in Guo et a ${ }^{19}$ and El Wakil et a ${ }^{17}$ trials was $15 \mathrm{~mm}$ while maximum balloon diameter was $20 \mathrm{~mm}$ in the other trials; however, we were not sure whether the results would be affected by this difference. Third, only three of the included trials reported the use of post-endoscopy biliary drainage. This may lead to bias in the result of PEP rate, and further subgroup analysis could not be implemented because of the lack of detailed information.

\section{Conclusion}

EPLBD alone was comparable to EPLBD with prior EST during ERCP in patients with large and/or multiple CBDSs. Although there were advantages in the rate of initial success, the frequency of ML usage, the rate of PEP, and total procedure time, these results were not statistically significant. Further studies are required to confirm the mechanisms of PEP in patients undergoing EPLBD during ERCP. 

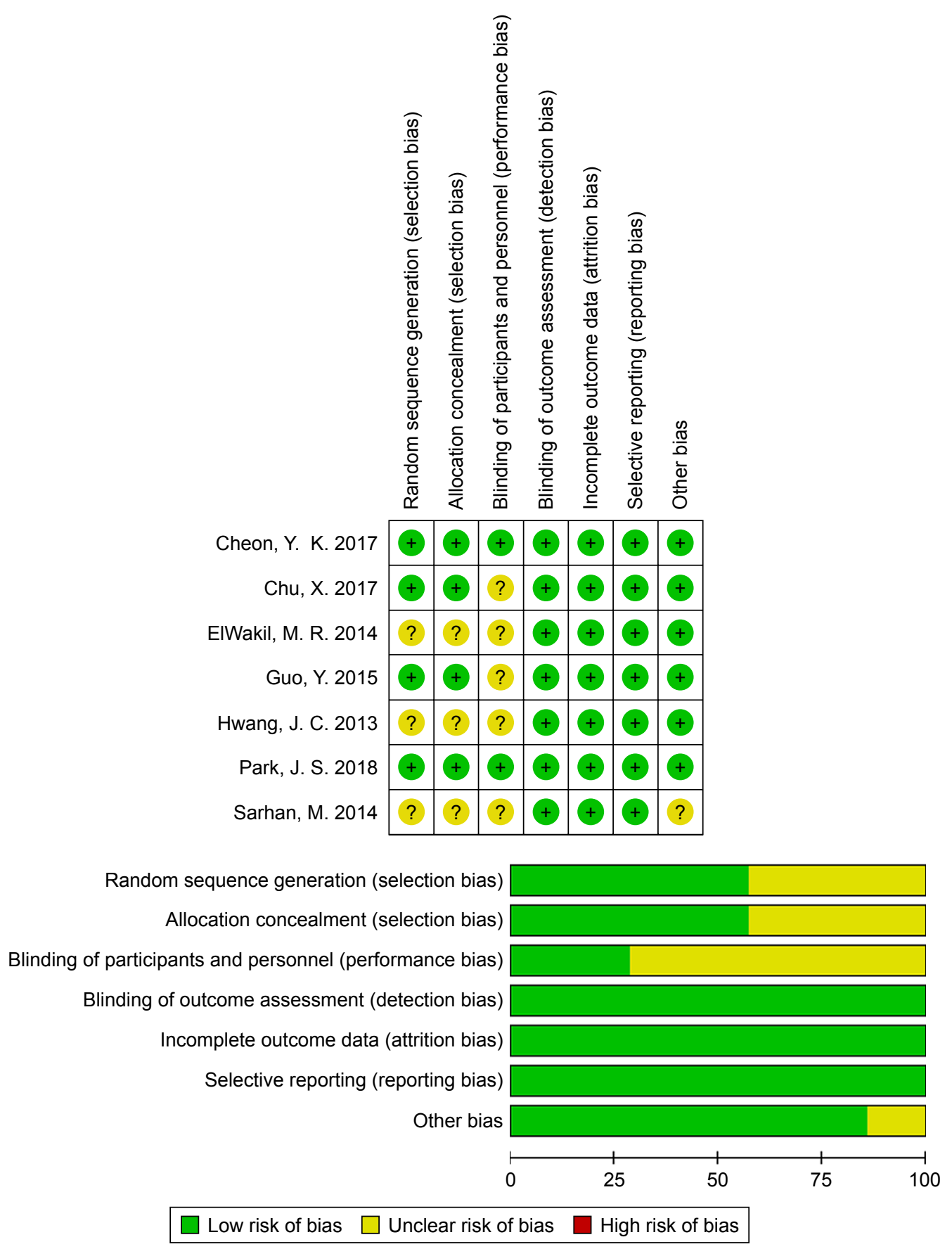

Figure 4 Risk of bias summary and risk of bias graph.

\section{Disclosure}

The authors report no conflicts of interest in this work.

\section{References}

1. Kawai K, Akasaka Y, Murakami K, Tada M, Koli Y, Nakajima M. Endoscopic sphincterotomy of the ampulla of Vater. Gastrointest Endosc. 1974;20(4):148-151.

2. Staritz M, Ewe K, Meyer Zum Büschenfelde KH. Endoscopic papillary dilatation, a possible alternative to endoscopic papillotomy. Lancet. 1982;1(8284):1306-1307.

3. Liu Y, Su P, Lin S, et al. Endoscopic papillary balloon dilatation versus endoscopic sphincterotomy in the treatment for choledocholithiasis: a meta-analysis. J Gastroenterol Hepatol. 2012;27(3):464-471.
4. Ito K, Masu K, Kanno Y, Ohira T, Noda Y. Ampullary intervention for bile duct stones in patients with surgically altered anatomy. Dig Endosc. 2014;26(Suppl 2):116-121.

5. Weinberg B, Shindy W, Lo S; Cochrane Hepato-Biliary Group. Endoscopic balloon sphincter dilation (sphincteroplasty) versus sphincterotomy for common bile duct stones. Cochrane Database Syst Rev. 2006; 33(1):Cd004890.

6. Ersoz G, Tekesin O, Ozutemiz AO, Gunsar F. Biliary sphincterotomy plus dilation with a large balloon for bile duct stones that are difficult to extract. Gastrointest Endosc. 2003;57(2):156-159.

7. Jin PP, Cheng JF, Liu D, Mei M, Xu ZQ, Sun LM. Endoscopic papillary large balloon dilation vs endoscopic sphincterotomy for retrieval of common bile duct stones: a meta-analysis. World J Gastroenterol. 2014; 20(18):5548-5556. 
8. Fujisawa T, Kagawa K, Hisatomi K, Kubota K, Nakajima A, Matsuhashi N. Endoscopic papillary large-balloon dilation versus endoscopic papillary regular-balloon dilation for removal of large bile-duct stones. J Hepatobiliary Pancreat Sci. 2014;21(6):405-409.

9. Hakuta R, Kawahata S, Kogure H, et al. Endoscopic papillary large balloon dilation and endoscopic papillary balloon dilation both without sphincterotomy for removal of large bile duct stones: a propensitymatched analysis. Endoscopy. 2018; Jun 26 [Epub ahead of print].

10. Doshi B, Yasuda I, Ryozawa S, Lee GH. Current endoscopic strategies for managing large bile duct stones. Dig Endosc. 2018;30(Suppl 1): $59-66$.

11. Itoi T, Ryozawa S, Katanuma A, et al. Japan Gastroenterological Endoscopy Society guidelines for endoscopic papillary large balloon dilation. Dig Endosc. 2018;30(3):293-309.

12. Kim TH, Kim JH, Seo DW, et al. International consensus guidelines for endoscopic papillary large-balloon dilation. Gastrointest Endosc. 2016; 83(1):37-47.

13. Park JS, Jeong S, Lee DK. Comparison of endoscopic papillary large balloon dilation with or without endoscopic sphincterotomy for the treatment of large bile duct stones. Endoscopy. 2018; Jul 3 [Epub ahead of print].

14. Liberati A, Altman DG, Tetzlaff J, et al. The PRISMA statement for reporting systematic reviews and meta-analyses of studies that evaluate healthcare interventions: explanation and elaboration. $B M J$. 2009;339:b2700

15. Hozo SP, Djulbegovic B, Hozo I. Estimating the mean and variance from the median, range, and the size of a sample. BMC Med Res Methodol. 2005;5(1): 13 .

16. Hwang JC, Kim JH, Lim SG, et al. Endoscopic large-balloon dilation alone versus endoscopic sphincterotomy plus large-balloon dilation for the treatment of large bile duct stones. BMC Gastroenterol. 2013; 13(1):15.

17. El Wakil MRM, Abdelkader NA, Salem HE-DM, Halima Abo AS. Different techniques for management of common bile duct stones: a single centre experience. J Egypt Soc Parasitol. 2014;44(3): 539-546.

18. Sarhan M, Enaba M, El-Bedewy M. El Raouf Sarhan Sarhan MEA. Is combination of biliary sphincterotomy and balloon dilation a better option than either alone in endoscopic removal of bile duct stones? A comparative study. J Gastroenterol Hepatol. 2014;29:154.
19. Guo Y, Lei S, Gong W, et al. A preliminary comparison of endoscopic sphincterotomy, endoscopic papillary large balloon dilation, and combination of the two in endoscopic choledocholithiasis treatment. Med Sci Monit. 2015;21:2607-2612. http://cochranelibrary-wiley.com/o/ cochrane/clcentral/articles/572/CN-01097572/frame.html

20. Cheon YK, Lee TY, Kim S-N, Shim CS. Impact of endoscopic papillary large-balloon dilation on sphincter of Oddi function: a prospective randomized study. Gastrointest Endosc. 2017;85(4):e781:782-790.

21. Chu X, Zhang H, Qu R, et al. Small endoscopic sphincterotomy combined with endoscopic papillary large-balloon dilation in the treatment of patients with large bile duct stones. Eur Surg. 2017;49(1):9-16. http://cochranelibrary-wiley.com/o/cochrane/clcentral/articles/294/ $\mathrm{CN}-01332294 /$ frame.html

22. Kamada K, Itoi T, Sofuni A, et al. Su1641. Efficacy and safety of EPLBD for bile duct stones in patients with surgically altered anatomy: a large case series at single high volume center. Gastrointest Endosc. 2015; 81(5):AB362.

23. Testoni PA, Mariani A, Aabakken L, et al. Papillary cannulation and sphincterotomy techniques at ERCP: European Society of Gastrointestinal Endoscopy (ESGE) Clinical Guideline. Endoscopy. 2016;48(7):657-683.

24. Park $\mathrm{CH}$, Jung JH, Nam E, et al. Comparative efficacy of various endoscopic techniques for the treatment of common bile duct stones: a network meta-analysis. Gastrointest Endosc. 2018;87(1):e10:43-57.

25. Li QL, Gao WD, Zhang C, et al. Is endoscopic sphincterotomy plus large-balloon dilation a better option than endoscopic large-balloon dilation alone in removal of large bile duct stones? A retrospective comparison study. Indian J Cancer. 2015;51(Suppl 2):e13-e17.

26. Park JS, Kim TN, Kim KH. Endoscopic papillary large balloon dilation for treatment of large bile duct stones does not increase the risk of post-procedure pancreatitis. Dig Dis Sci. 2014;59(12):3092-3098.

27. Fujisawa T, Kagawa K, Hisatomi K, Kubota K, Nakajima A, Matsuhashi N. Is endoscopic papillary balloon dilatation really a risk factor for postERCP pancreatitis? World J Gastroenterol. 2016;22(26):5909-5916.

28. Park SJ, Kim JH, Hwang JC, et al. Factors predictive of adverse events following endoscopic papillary large balloon dilation: results from a multicenter series. Dig Dis Sci. 2013;58(4):1100-1109.

29. Huang Q, Shao F, Wang C, Qi W, Qiu LJ, Liu Z. Nasobiliary drainage can reduce the incidence of post-ERCP pancreatitis after papillary large balloon dilation plus endoscopic biliary sphincterotomy: a randomized controlled trial. Scand J Gastroenterol. 2018;53(1):114-119.
Therapeutics and Clinical Risk Management

\section{Publish your work in this journal}

Therapeutics and Clinical Risk Management is an international, peerreviewed journal of clinical therapeutics and risk management, focusing on concise rapid reporting of clinical studies in all therapeutic areas outcomes, safety, and programs for the effective, safe, and sustained use of medicines. This journal is indexed on PubMed Central, CAS,

\section{Dovepress}

EMBase, Scopus and the Elsevier Bibliographic databases. The manuscript management system is completely online and includes a very quick and fair peer-review system, which is all easy to use. Visit http://www.dovepress.com/testimonials.php to read real quotes from published authors. 